\title{
Changing of the climate
}

Volume 6 Issue 6 - 2017

\begin{abstract}
The man destroyed and continues to destroy the biota: more than $60 \%$ of the land was used for arable land, artificial reservoirs, landfills, asphalted and concrete areas of cities and roads. ${ }^{1}$ This picture was taken from the side of the plane over Europe. There is not a single piece of land untouched by man.

The area occupied by the humanity itself is insignificant, only $4 \%$, but the number of floors of buildings and structures raises it several times. It is enough to understand that each heating of water, each washed cup and object, from the body to the asphalt, replenishes the atmosphere with evaporation, alien to nature. There are such data that each person spends 200-300 liters of water a day, but only 2-3 liters of this volume a person uses for the purpose of nature - for drinking. These 2-3 liters leave the body of a person, each living being, each plant in the form of special fumes, mainly through breathing. It cannot be that these evaporation and evaporation from the asphalt or the drying laundry washed are the same. It is known that the evaporation of a person's exhalation determines his illness. It is urgently needed to study organic fumes and compare their parameters with artificial evaporation. This analysis can be the main evidence of these assumptions.
\end{abstract}

\section{Oleg Halidullin \\ Kazakh National University Alb Farabi Russia}

Correspondence: Oleg Halidullin Kazakh National University Junior researcher Alb Farabi Russia, Email 71 15215@mail.ru

Received: August 28, 2017| Published: December 29, 2017

Keywords: Climate change, Water cycle, Anthropogenic cycle, Natural evaporation, Artificial evaporation, Global concept

\section{Introduction}

Millions of years on Earth created a favorable climate. The main instrument of this construction was the balance of the circulation of various substances between the atmosphere and the biota. One of the main elements of the circuit is water. Precipitation falls in a given zone in a given volume, with a predetermined sequence. In accordance with the needs of the inhabitants of the zone. Inhabitants of these zones or biota - the community of animal and plant life returned moisture to the sky with their breathing and transpiration. There was harmony, a certain rhythm and climatic comfort. Heating the soil leads to evaporation and increased cloudiness. Clouds shade the soil and reduce solar radiation - evaporation decreases - clouds decrease - radiation increases. Conversely, intensification of sunlight activates plant growth, development and activity of biota, increases volatility. It is the symbiosis of atmospheric phenomena and biota that created the climate of the whole planet for the weather for every point of the earth. And at every point, in accordance with the needs of its inhabitants. The atmosphere gave out exactly as much water as necessary for this area (Figure 1).

Immense evaporation is produced in municipal and industrial processes, carried out around the clock and year-round. Numerical data are not available, but it is enough to imagine these volumes that such water consumption is unnatural, nature is not provided for, and the rate of water consumption increases in proportion to the growth of the world's population, raising productivity in all areas, and the release of new goods. The manufacture of each item requires water flow. For example, 1000 liters of water per $1 \mathrm{~kg}$, cheese 2500 liters of water per $0.5 \mathrm{~kg}$, beef 4500 liters of water per 1 steak. Production is all the things around us from the needle to the brick in the walls, the dishes and the computer on the table and the plane in the sky. All these expenses are unnatural, alien to nature. After consumption, the water merges into the sewage system and evaporates from sedimentation tanks and oceans.

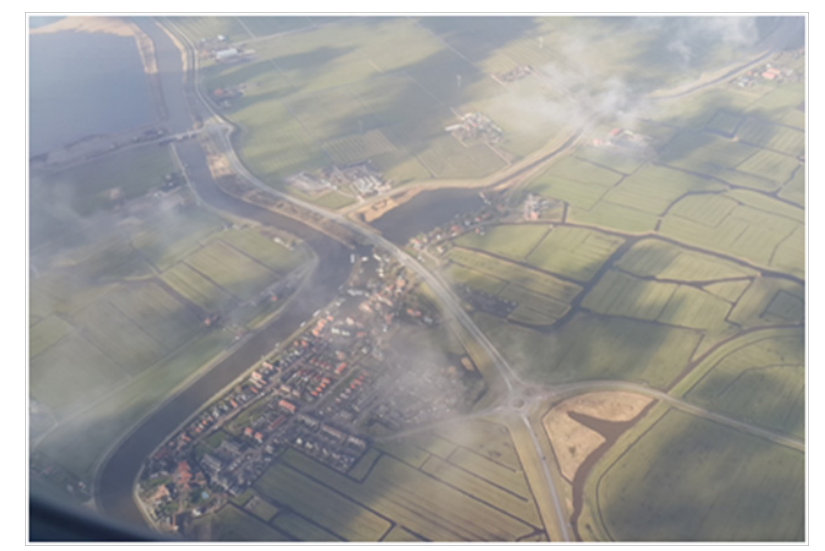

Figure I This picture was taken from the side of the plane over Europe.There is not a single piece of land untouched by man.

The volumes are huge and growing every day. And every day in different parts of the world there are floods. This is the reaction of water to the relation of land to it in a single chain of transformations. Unprocessed water, repeatedly falling into a short circuit, anomalous water, shows its unknown to us new qualities. Gathering in huge clouds, it is outrageous with typhoons, cyclones, storms, pours out massive sediments, overflowing rivers, looking for a job - coming out on the ground, warns us. Forms weather and climate.

We have reduced the functionality or the main purpose of water to feed the biota. One hectare of soil contains 20 tons of underground living creatures, ${ }^{2}$ each unit that awaits rainwater. The rate of evaporation from the breathing of this creature is quite economical for its existence and reproduction. Biota accumulates water and carefully consumes it to the next precipitation, converts it into blood, juices, moisture from breathing and transpiration. Water, which is taken from 
nature, is excommunicated from its natural functions. With asphalt, dumps, arable land, artificial reservoirs, flood floods, part of the water goes underground, merging into aquifers, the other evaporates. If you visualize the rate of evaporation of water from asphalt and the same amount of water from the same area of natural grass cover, you can be sure that water will go to the sky many times faster than from the breathing of underground living creatures and transpiration of plants. Hence the conclusion follows that the volumes of water of artificial fumes far exceed the natural ones, and everything that was raised into the atmosphere, deprived of its meaning, natural functions, can fall out in any place and flood it with floods at any time. This we see almost daily in various Regions of the planet. Catastrophically, the natural link disappears - the transformation of water in the organic. Mankind evaporates water day and night, all the year round. And the volumes of these artificial fumes increase with acceleration. There is a new cycle of water, of unnatural origin. Water makes a circuit without performing its natural mission - go through food chains. Everything in our world is interconnected. Each action has its consequences. The increased volumes of artificial fumes with increased intensity of evaporation create a new regularity, another cycle of the water cycle. But no longer nature, but a cycle of artificial fumes or a cycle of anthropogenic, alien to nature. The mechanism of natural regulation is broken. The old reference materials show the following ratio of greenhouse gases in the atmosphere:

\section{$\mathrm{H}_{2} \mathrm{O}$ water vapor $36-72 \%$,}

Carbon dioxide $\mathrm{CO}_{2} 9-26 \%$,

\section{Methane CH44 9\%}

Ozone $\mathrm{O}_{3} 3-7 \%$.

Obsolete data, but water vapor more than anything else more than double even on these data and this content is increasing with new technologies. It is not known how fast in terms of speed, how much larger in volume, this growth is, but the increase in cloudy days and the increase in the number and destructiveness of floods speaks precisely for this. This is also evidenced by the abundant rains in Peru, floods in Australia, increased snow cover in the vast steppes of Kazakhstan in recent winters with the flooding of settlements and cities. Water vapor, condensing into droplets, hangs in the air in a state of clouds and clouds, blocking the arrival of solar heat. These clouds are the main element of the impact on weather and climate. Why are there often cold days in the summer? Because the clouds thicken in an impenetrable veil of kilometer thickness. Therefore, the climate does not change the greenhouse blanket with carbon dioxide, namely, water clouds. To prove this factor, new measurements are needed to make up the atmosphere. We believe that these measurements will lead to the proof of this hypothesis. Humanity took this dogma as the basis and went on the wrong path to reduce the impact on the greenhouse layer of the atmosphere of carbon dioxide. Carbon dioxide is a private one, one of the elements of the circuit, its content is insignificant in comparison with the volumes of water vapor in the atmosphere. His participation in the penetration of radiation is much less than the volume of water in the clouds. The decisive factors of influence on them are the cloud cover of immense sizes, forms, stability of existence, abundance of condensation, intensity of growth and emptying. The evaporation cycle involves all other components of the atmosphere, including carbon dioxide, in its process and turnover. It is consumed more by plants on a sunny day, promotes plant growth and increases the yield of oxygen and moisture. Thus, a new source of anthropogenic impact on climate is determined - artificial evaporation - a new water circuit. Urgent studies and confirmation of the proposed direction are needed. On their basis - the development of a new global concept, rethinking the entire population of the planet the nature of the destruction of natural phenomena. To preserve the habitat for our descendants, we must begin now to restore the natural evaporation the basis of the universe. The new concept can be based on:

a. Urgent development of alternative energy in order to stop the construction of dam power stations with flooding of riverine habitats

b. Total saving of water consumption is necessary. To revise all production and utility processes with the transfer of water consumption into closed cycles.

c. Reconstruction of agriculture, transition to drip irrigation, reduction of irrigation systems, and non-plowing.

d. Stopping soil contamination with landfills and dumps and reclamation of existing dumps. Creation of non-waste technologies.

e. Reduce washing of everything that is washed and dried. There are, and need to develop new, methods for dry cleaning of objects and surfaces, for example, cars, cleaning of asphalt pavements and roads.

f. Outdoor landscaping of buildings and structures. The walls and roofs of buildings and all structures can be covered with vegetation. For example, ${ }^{3}$

g. Gradual transition to underground and underwater construction, starting from the development of ores, dressing, smelting, obtaining a finished product - all this can be done underground, in the worked out spaces. If it's metals, metal products and other metal-consuming products are exported to the surface.

If it is oil, only fuel is output. If it is uranium, then electricity is output. All types of production must be located underground. And then everything else, down to the shelter. There are many shopping areas and metro in many large cities. There are real projects of underwater and underground cities. For example, ${ }^{4}$ There are underground greenhouses, where all the greenery is grown all year round.

\section{Conclusion}

Only general mobilization in this direction can restore natural evaporation and the natural circulation of water. This is the only way to return A comfortable climate. Of course, all this is not done suddenly, right away. But on a reasonable scale, humanity must gradually come to this. And our duty is to leave our offspring a normal climate, exclude natural disasters. The hypothesis requires proof, research. It is necessary to urgently cooperate new specialists who will see the idea and organize a campaign against dogma. Our planet needs salvation.

\section{Acknowledgements}

None.

\section{Conflicts of Interest}

None.

\section{References}

1. http:/geographyofrussia.com/razrushenie-estestvennyx-ekosistem/

2. http://smoldacha.ru/osnovy_prirodnogo_zemledeliya.html

3. http://happymodern.ru/vertikalnoe-ozelenenie-58-foto-interesnyjsposob-ekonomii-prostranstva/ http://sadovodka.ru/posts/2712vneshnee-i-vnutrennee-ozelenenie-zdanii.html

4. http://gearmix.ru/archives/2174 